\title{
PROCESSO DE TRABALHO DA ENFERMAGEM NA ATENÇÃO AMBULATORIAL AO ADULTO COM HIPERTENSÃO ARTERIAL: REPRESENTAÇÕES E CONTRADIÇÕES ***
}

\author{
Marcia Regina Car* \\ Emiko Yoshikawa Egry**
}

CAR,M.R.; EGRY.E.Y. Processo de trabalho da enfermagem na a tenção ambulatorial ao adulto com hipertensão arterial:representaçoes e contradiçoes. Rev. Hsc. Hnf.USP. v.29. n.2, p. 180-92, ago. 1995 .

Ao buscar compreender o fenômeno da assistência à saúde, com ênfase na enfermagem, da Liga de Hipertensão Arterial do Hospital das Clínicas da Faculdade de Medicina da USP,as suas contradições foram evidenciadas através da articulação dos elementos constitutivos destes processos de trabalho.contidos nos depoimentos de seus agentes. As concepções dos agentes expressaram uma práxis reiterativa, limitando o trabalho da enfermagem como Meio do processo de trabalho médico tanto na face assistencial como na de pesquisa. Na face assistencial do seu processo de trabalho a enfermagem reitera o saber que sustenta a Finalidade $e$ o recorte do Objeto do trabalho médico porém, este saber parece esvaziar-se enquanto Meio do trabalho da enfermagem. O ensino de enfermagem, representado como produto de uma integraçāo com esta prática, termina por reproduzir o seu saber esvaziado de significado mas que,por ser a-crítico.legitima sua falsa neutralidade.

INITERMOS:Processo de Trabalho.Hipertensão Arterial.Saúde do Adulto.

\section{INTRODUÇÃO}

()s serviços de saúde têm sido estruturados no Rrasil. de modo geral. de acordo com o paradigma médico-biologico da doença. Assim, o atendimen-

* Enfermeira. Doutora em Enfermagem. Professora Doutora do Departamento de Enferma gem Médico-Cirúrgica

* Enfermeira. Doutora em Saúde Pública. Professora Associada do Departamento de Enfermagem em Saúde Coletiva,EEUSP.

*** Parte da Tese:CAR.M.R. Da aparência à essencia:a práxis assistencial dos trabalhadores da Liga de Hipertenrterials no. Sáo Paulo,1993. 125p. Tese de (Doutorado)-Escola de Enfermagem. Universidade de Săo Paulo. 
to dos adultos com hipertensão arterial que têm acesso aos serviços públicos de saúde é realizado consoante o modelo clínico individual, e ainda, hipervalorizando a ação do profissional médico. Nesses serviços, a enfermagem desenvolve atividades tais como a pró e a pós consulta médica e outras ações ditas educativas, no sentido de orientar o doente para o tratamento médico estabelecido, configurando o atrelamento de suas ações ao mesmo paradigma.

$\Lambda$ s discussões sobre as limitações decorrentes do paradigma biologico da doença e do modelo clínico que lhe é correspondente, intensificaram-se na América Latina a partir do final dos anos 60, época em que foi sendo reconhecida a importância do conhecimento das ciências sociais enquanto instrumental teorico-conceitual e metodologico para as reflexões sobre a prática, no campo da saúde.

$O$ entendimento de que o processo saúde-doença tem vínculos estreitos com o modo como está dada a organização social não é recente. Embora ele já existisse no século passado, foi desprezado pelo enfoque biologico que prometia ter. efetivamente teve, avanços rápidos na medicina. Assim, afirmam LAURELL: BLANCO (1991), que "toda a atenção cientifica se concentrou no indivíduo e nos processos biológicos. deixando fora de seu campo de investi. gação a coletividade humana e a estrutura social na qual se inscrevia".

() ressurgimento dessa polêmica, nos anos 60 , encontra suas razóes tanto no desenvolvimento interno da medicina, como na sociedade com a qual cla se articula (LAURELL: 1983). () auge dessa polêmica encontra explicação na crescente crise política e econômica. que gera uma nova etapa de lutas sociais particulares, em diferentes países. Por outro lado, o principal motivo interno à medicina que dá origem ao questionamento do paradigma médico-biológico 6 encontrado na dificuldade de gerar conhecimentos que permitissem a compreensão dos problemas de saúde da coletividade, tais como. as doenças cárdio-vasculares e o câncer (LAURLLL_; 1983).

Surgiu assim um movimento contra-hegemônico que vem gerando, principalmente na $\Lambda$ mérica Latina, novos conhecimentos na área de saúde. $A$ contra-hegemonia 6 dada pela sua fundamentação no referencial tebrico-filosófico do materialismo histórico e dialético que se opõe à concepção idealista de mundo, representada pelo positivismo, dominante neste século na produção do saber na area da saúde.

Nesse referencial, o processo saúde -doença da coletividade é entendido como "o modo específico pelo qual ocorre no grupo o processo biológico de desgaste e reprodução, destacando como momentos particulares a presença de um funcionamento biologico diferente com conseqüencia para o desenvolvimento regular das atividades cotidianas, isto 6., o surgimento da doença" (LAURELL; 1983). 
Se essa visão de mundo não está hegemonicamente posta. os correspondentes conceitos tais como sociedade, homem e processo saúde-doenca também não estão sendo operacionalizados nos sistemas e serviços de saúde. Equivale dizer que predomina hoje a adoção de modelos tebricos-conceituais mais enraizados na fundamentação do funcionalismo-positivista. apesar da intensificação do processo de reflexão das práticas de saúde.

$\Lambda$ enfermagem brasileira, enquanto uma pratica social, vinculada as demais práticas em saúde não foge destas amarras das coneepcóes predominantes. Vem. no entanto, inserindo-se nesso movimento de transformaçăo na área da saúde consoante à concepça materialista da história produzindo. principalmente na década de 80 . reflexóes sobre a natureza de sua origem e do desenvolvimento de sua prática. Dentreos estudos realizados nessa

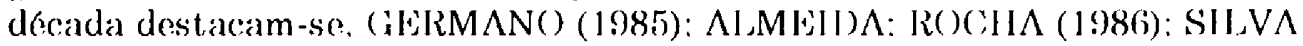
(1986): REZENI)E (1986): MEL() (1986): CASTELIANOS (1987) O IPRLS (1989).

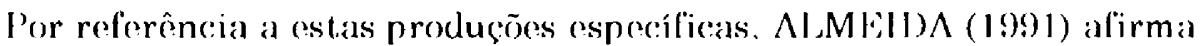
que elas possibilitaram macro-análises da enfermagem na formacão social capitalista. especialmente solore a sua genese e seu desenvolvimento histórico na socicdade brasileira.

Compreender a enfermagem como prática social e. assim sendo. como um trabalho constitutivo da produção de serviços en saúde. implica em revisar as concepcõos e as ações decorrentes dessa prática.

$\Lambda$ concepcẽo marxista do trabalho enquanto processo. vem sendo utili. zada como base para compreensão das práticas de saúde (iONC:AI VES (I988: $1992) 6$ um dos autores brasileiros. que vem produzindo importantes reflexões sol)re as práticas de saúde. fundamentadas nessa concepcão.

Este autor. superando a visão idealista das práticas de saúde conceloeas como trabalho. lim que pesem as especificidades concernentes a essas praticas. principalmente por terem como Objelo o homem. elas são trabalho porque se inserem sol determinadas estruturas sociais com os especílices modos de produção. Dessa forma, as praticas de saúde apresentam os mesmos elementos constilutivos do processo de trabalho humano em geral - Objeto, Meios e Finalidade.

Consoante essa concepcão, a pratica de enfermagem, inserida nas práticas de saúde também vem sendo apreendida como trabalho.

É essa consonância que levou a pesquisadora a re-olhar a prática da enfermagem da qual o um dos agentes. Essa pratica desenvolvida na liga de Diagnostico e Tratamento da Hipertensão Arterial do lospital das (Ylínicas da liaculdade de Medicina na Universidade de São l'aulo (I iga). não tem se mostrado transformadora da qualidade de saúde des usuários deste serviऽo. Nesse sentido. se faz necessária a revisão das concepsones que orientaam 
essa prática compreendendo-a como um trabalho, trabalho este que se desenvolve num micro espaço institucional concreto, articulado aos demais processos de produção em saúde.

$O$ trabalho da enfermagem desenvolvido na Liga, desde 1981, pela pesquisadora, enquanto um dos agentes dessa prática, foi gradativamente se tornando fonte de insatisfação gerando a necessidade de superar as limitações da compreensão quantitativo-descritiva, no sentido de buscar alternativas de transformação.

Até bem pouco tempo, a análise que era feita do trabalho da enfermagem na Liga, orientada pela concepção teórico-metodologica positivista, salientava aspectos referentes à sua forma sistematizada e aos seus resultados. Visto dessa maneira, desde o início dessa atividade buscou-se organizar e implementar instrumentos sistematizados para as açōes de enfermagem tais como a pré e pos-consulta médica e a consulta de enfermagem. () desenvol. vimento dessas estrategias visava principalmente melhorar a adesão do doente ao tratamento médico estabelecido para o controle da pressão arterial. ()s objetivos foram estabelecidos partindo-se do pressuposto de que, uma vez feito o diagnóstico e instaurado o tratamento médico, o doente deveria ser capaz de colaborar no controle da pressão arterial, necessitando assim ser orientado sobre a hipertensão arterial e seu tratamento específico.

Para atingir essa meta "(..) foram padronizadas condutas de enfermagem baseadas nos problemas prioritários: a própria doença hipertensiva, o regime alimentar. o tratamento medicamentoso, atividades físicas, hábitos como o fumo e o alcoolismo, e o fator emocional" (PIERIN et al.: 1981).

$\Lambda$ avaliação quantitativa da eficácia dessas condutas sobre o controle da pressão arterial, realizada em estudo comparativo entre 246 hipertensos acompanhados tambem por docentes e estudantes de enfermagem e 176 hipertensos acompanhados somente por médicos, permitiu verificar que não houve diferenças estatisticamente significativas no controle dos níveis pressóricos entre os dois grupos de doentes. Porem, verificou-se que a freqüencia de comparecimento as consultas médicas era significativamente maior no grupo de hipertensos atendidos tambem pela enfermagem. $\Lambda$ metodologia utilizada nessa avaliação foi consoante à concepção positivista (GIORGI et al.; 1985).

Wste foi o estudo mais abrangente realizado para a avaliar a prática da enfermagem realizada por docentes e discentes na liga e seus resultados monstraram que o seu produto não contemplava a finalidade proposta de controle da pressão arterial (GI()RCil et al:1985).

Há que se considerar. portanto. as limitações do instrumental teóricometodologico utilizado ate o momento para a análise da prática de enfermagem na liga. Tal como refere MINAYO(1992). a coneepsão funcionalista se 
manifesta na prática médica e nas suas relações com a sociedade :"(1) na concepção da saúde/doença como fenômeno apenas biológico individual em que o social entra, compreendido como modo de vida o apenas como variáael, ou é desconhecido e omitido: (2) na valorização excessiva da tecnologia e da capacidade absoluta da medicina de erradicar as doenças: (3) na dominacão corporativa dos médicos em relação aos outros campos do conhecimento, adotando-os de forma pragmática (...); no tratamento subalterno dado aos ou tros profissionais da area (enfermeiros, assistentes sociais. nutricionistas. atendentes, etc...); em relação ao senso comum da população. numa tentativa nunca totalmente vitoriosa de desqualifica-lo e absorvê-lo". (grifos nossos)

A compreensão do fenômeno saúde-doença, no recorte do adulto com hipertensão, necessita recuperar os paradigmas da epidemiologia social e entender as reais causas e determinantes do problema da hipertensão arterial. Por sua vez a enfermagem necessita, tambem. buscar compreender o seu processo de trabalho na liga. que enquanto concebido como prática social implica, para isso, na adoção de um outro referencial teórico-filosófico. Neste sentido, o materialismo historico e dialético enquanto referencial de interpretação e análise vai além da aparência fenomênica do objeto. buscando conhecer sua subslância ${ }^{*}$ e sua articulação com a estrutura social cada vez mais ampla.

Este estudo pretendeu, pelas razóes expostas anteriormente. evidenciar as contradiçóes existentes no fenômeno da atenção da enfermagem na Liga de Hipertensão Arterial elucidando-as através da articulação dos elementos constitutivos do processo de trabalho. contidos na narrativa assistencial dos agentes do trabalho na liga. Compreende-se ainda, que atraves do processo de dialetização possam ser visualizados os caminhos para a transformação das ações assistenciais do referido Serviço.

Serão utilizados para tanto os instrumentos de captação e interpretacão da realidade objetiva. compativeis com o refereneial teórico-filosofico adotado. Para alcançar a finalidade proposta, o presente estudo teve por objetivos:

evidenciar as contradições existentes na prática de saúde da en. fermagem na Liga de Hipertensão Arterial:

* Kosik explica que o marxismo definiu como "substáncia" a dinâmica do objeto. a sua dialética. Por conseguinte, conhecer a substáncia náo significa reduzir os "fenômenos" à substância dinamizada. vale dizer a algo que se esconde por detrás dos fenômenos e que deles năo depende; significa conhecer as leis do movimento da coisa em si. A "substância é o próprio movimento da coisa ou a coisa em movimento". KOSIK. K. Dialética do concreto. Rio de Janeiro. Paz e Terra. 1986. p. $27-8$ 
- evidenciar as rázes ideologicas dos saberes que orientam os processos de trabalho na Liga;

- interpretar historicamente a dinâmica das transformações da prática assistencial da enfermagem na Liga de Hipertensão Arterial:

\section{MÉTODO}

$\Lambda$ fundamentação teorico-metodologica deste estudo está baseada na teoria marxiana.intermediada pelas categrorias analíticas dos processos de trabalho e de saúde-doença.

O) material empírico deste estudo foi obtido atraves de entrevista com dez agentes médicos e de enfermagem que atuavam na liga no momento. Deles foi solicitada a descrição de uma situação vivenciada de atendimento na Liga no qual estivessem envolvidos o proprio profissional. o doente e outros agentes.

()s depoimentos obtidos através dessas entrevistas foram gravados. transcritos e submetidos a análise qualitativa fundamentada em FIORIN:SAVIOLI(1991), que permitiu a extraça dos temas contidos na narrativa assistencial dos agentes.

()s temas deprendidos desses discursos foram expressos em frases temáticas agrupadas atraves de suas articulaçoes com os elementos constitutivos do processo de trabalho, ou seja. Objelo, Finalidade e Meios/ Instrumentos.

\section{3 - DIALÉTICA DO PROCESSO DE TRABALHO DA ENFERMAGEM NA LIGA DE HIPERTENSÃO ARTERIAL}

Evidenciam-se poucas contradições no processo de trabalho da enfermagem na liga, visto em sua interioridade. Não se pode afirmar o mesmo quando se analisa sua exterioridade. ou seja. suas articulações com totalidades maiores determinantes desse trabalho em saúde.

()s depoimentos dos agentes do tralualho na liga permitiram pereeber o trabalho da enfermagem como pouco expressivo. do ponto de vista da intervenção assistencial propriamente dita da enfermagem, denotando muito mais um trabalho de apoio ao processo de trabalho médico. 
'Tomando-se o doente como objeto, historicamente idealizado, da intervenção da enfermagem no modelo clínico-biológico, ele foi delimitado por um olhar a-histórico, a-crítico que desconsidera os determinantes sociais do processo saúde-doença como ilustra a frase temática de um dos agentes do trabalho da enfermagem na Liga:

O doente é a pessoa que lem uma doença crônica (hipertensão arterial) e que vice a vida do dia a dia, porém a doenca inlerfere em suas atividades, na sua condição de vida e trabalho.

Lsta representação concebe a normalidade de um cotidiano. indiferenciado por classes sociais. Na manifestação do pólo doença as condicões de vida e trabalho não são consideradas determinantes. Ainda. as concepçoes reiteram o princípio idealista que vem orientando hegemonicamente o trabalho em saúde na nossa sociedade. ou seja. o princípio político-ideologico da igualdade.

I AURELL (1983) apontia para a compreensão desta visão sobre o processo saúde - doença nas sociedades capitalistas: "(...) o conceito de doença explícita está centrado na biologia individual. fato que lhe retira o carater social. () conceito de doenca oculta. quer dizer, que está subjacente na definisão social do que e doença. refere-se à incapacidade de trabalhar (...)".

E. portanto dessa forma que a enfermagem da liga percebe a doenca ou seja. interferindo na vida das pessoas impedindo-as ou limitando-as para o trabalho. Assim. o doente passa a adquirir uma responsabilidade social. como ilustra a frase tematica de um dos agentes da enfermagem:

O doenle lem um decer-fazer o lralamento para melhorar e para isso necessila de um poder e de um saber. O poder se refere às condiçôes financeiras para seguir a diela recomendada. () saber se refere aos conhecimentos que lhe são Iransmilidos pelos profissionais.

Assim, o objelo de trabalho da enfermagem - o doente abstrato - passa a se concretizar como um corpo humano doente, não adequado como força de trabalho. Percebe-se que a limitação do olhar (saber) que recorta o doente como um corpo biologicamente alterado. nada tem da "neutralidade científiea" propagada pelo positivismo pois, responde diretamenter aos custos sociais do corpo humano incapacitado para o trabalho. gerando um dado curar necessário. como finalidade do trabalho em saúde.

Analisando ainda a compreensão dos agentes do trabalho de enfermagem solbre o doente. enquanto objeto de suas intervençoes. duas outras necessidades lhes foram atrilouidas alem do dever-fazer ot tratiamento: um poder o um saber.

A necessidade do doente ter eondiçoes financeiras para segruir o trata- 
mento prescrito parece limitar-se a um poder de consumo. Este poder não foi relacionado aos seus determinantes sociais, ou seja, à inserção do sujeito no modo de produção capitalista que resulta diretamente na sua qualidade de vida.

O saber referido pelos agentes parece tratar-se dos conhecimentos técnicos que seriam necessários para que o doente realize as condutas estabelecidas pelo médico. Para isso, os agentes da enfermagem assumem a intermediação entre o doente e o médico, através da transmissão de conhecimentos técnicos ao doente. Assim, o que justificaria as ações da enfermagem ê um saber técnico acerca da saúde que o doente não detém.

O significado da influência destas informações técnicas na vida do doente não foi mencionado, ou seja, o saber técnico acerca da saúde que o profissional médico detém foi assumido como norma inquestionável que o sujeito deve cumprir. Portanto, nesse acesso às informações há uma relação de dominação do tecenico instituído sobre a vida das pessoas.

Nesse sentido, os depoimentos dos agentes da enfermagem apontam ainda para uma valorização positiva do doente quando ele se mostra resignado e submisso, como ilustra a frase temática a seguir:

A enfermeira valoriza positivamente a experiência de consulta ao hipertenso por haver acatamento e submissão deste a ela, quando colocado em oposição ao doente da imunologia.

Re-olhando o objeto do processo de trabalho da enfermagem na Liga, representado por seus agentes, alem de ser um corpo humano incapacitado (doente) para o trabalho. vem se delineando como sendo incompetente no nivel do saber (ténico) para seguir o tratamento instituido. Esse tratamento deveria ser, no dizer dos agentes da enfermagem, passivamente seguido, independentemente dos determinantes sociais do poder - potencial ou real - de consumo do doente.

$\Lambda$ finalidade idealizada do processo de trabalho da enfermagem na Liga, expressa nos depoimentos dos agentes médicos e da enfermagem, ou seja, garantir a adesão do doente ao tratamento medicamentoso, 6 coerente com a finalidade do tratamento médico de normalizar a pressão arterial, através do uso de medicamentos. $\Lambda$ frase temática abaixo ilustra esta afirmação:

A ação assistencial da enfermagem na Liga restringe-se ò orientação enfática do doente, para que este tome a medicação prescrila.

O trabalho da enfermagem como meio/instrumento do processo de trabalho médico fica assim reafirmado. Ademais, a enfermagem, ao assumir subordinadamente a finalidade de garantir a adesão do doente ao tratamento medicamentoso, limita-se no nível do (des)conhecimento, as possiveis razões do abandono do tratamento pelo hipertenso. 
As concepcões dos agentes da enfermagem sobre a estratégia de obter essa "garantia de adesão", acabam por esvaziar este saber técnico, chegando no nivel do convencimento através da obtenção da confiança pessoal do doente-individuo no individuo-trabalhador (agente de enfermagem).

As frases temáticas abaixo expressam e ilustram esta afirmação:

A atenção que a enfermeira dispensa ao doente eslabelece uma relação de confianca, o que favorece que ele execute melhor o tratamento.

A enfermeira sabe convencer o doente para que ele tenha maior adesão ao tratamento médico.

O conceito de assistência é definido por "ser útil ao doente, criando um elo afetivo (inspirar confiança) ajudando-o emocionalmente por ouvilo. Os resultados dessa assistência são salisfatórios para o serịço e. para os profissionais".

Através dessa última frase temática expressa por um dos agentes, percebe-se num primeiro plano, a reiteracão do modelo burguês utilitarista claramente presente na finalidade do trabalho da enfermagem. No segundo plano, o saber que orienta as intervenções da enfermagem está sendo substituido por um "elo afetivo". obtido através da ação "ouvir", considerando-a um fim em si mesma. Portanto permanece completamente esvaziado de conhecimentos técnicos, mesmo na visão científica positiva.

Por fim, reforçando a idéia do produtivismo. a prática da enfermagem na Liga foi considerada "...satisfatória para o serviço e para os profissionais", ou seja, o doente, suposto objeto da intervenção, ex excluído inclusive da avaliação dessa prática. $\Lambda$ sua participação fica portanto restrita ao dever-executar as condutas estabelecidas.

Apesar disso, a fala de um deles aparenta uma integralidade do objeto e da finalidade do processo de trabalho da enfermagem:

"A consulta de enfermagem visa atender ao individuo como um todo, nos seus aspectos relacionados à doença (aspectos biológicos, hipertensão propriamente dita) e sociais (vida do dia a dia, relacionamentos dessas pessoas, meio em que vive)".

No entanto, essa aparente integralidade da finalidade do trabalho da enfermagem na liga to tão idealizada como o seu objeto - "o indivíduo como um todo". Essa retórica tem suas raízes na busca da enfermagem em definir um campo específico de conhecimentos, atraves do desenvolvimento das Teorias de Enfermagem. Essas teorias desenvolvidas principalmente por enfermeiras norte-americanas, vêm sendo difundidas entre nós atraves dos meios acadêmicos com os agentes acadêmicos da enfermagem passando a incorporar, nos seus discursos, os conteúdos inerentes a essas teorias."(...) 
este homem de quem as teorias falam é de um nível de generalização muito grande, 6 um todo biopsicossocial em interação com o meio ambiente temporoespacial, perdendo, desta maneira, sua historicidade e concretude, passando a ser universal"(ALMEID $\Lambda ; R O C H A ; 1986)$.

() desenvolvimento destas teorias, de modo geral, não vem influenci. ando a prática de enfermagem brasileira, porém parece ter sido incorporado ao discurso acadêmico, o reprodutor de uma visão idealista de mundo, por excelência.

A concep̧ão representada no "indivíduo total em seus aspectos biológicos e sociais" reitera o modelo epidemiológico tradicional onde o todo equivale à soma das partes, que fatorando o objeto de intervenção permite respostas práticas mas, impede a compreensão da saúde-doença como processo articulado aos processos sociais.

No trabalho da enfermagem na Liga, as intervencões baseadas em fátores de risco não vêm atingindo o resultado prático descijado, de controlar os níveis da pressão arterial dos doentes. Porem. os agentes deste trabalho, ao inves de questionarem esta prática e a teoria que a tem orientado, enquanto insuficiente para a aproximação do sujeito bio-social deste processo, derivaram suas intervenções para um nível de relação interpessoal, aparentemente laica. $\Lambda$ frase temática abaixo ilustra essa afirmação:

A consulta de enfermagem proporciona a conversa enlre a enfermeira e o doente permitindo a ele o desabafo.

A finalidade dessa intervenção da enfermagem não está claramente posta, mas parece articular-se àquelas representações dos agentes do trabalho da enfermagem que propõem "o estabelecimento de uma relação de confiança" entre o doente e a enfermeira, para olter do primeiro a adesão ao tratamento medicamentoso prescrito pelo médico.

Èm relação aos meios/instrumentos do processo de trabalho da enfermagem observa-se um esvaziamento do saber que deveria orientar essa prática assistencial.

Essas açōes limitaram-se ao "ouvir", "dar atenção", "orientar nas suas necessidades". "conversar" para olter a "confiança" e a criar um "elo afetivo" com o doente.

() único instrumento para intervenção assistencial, apontado pelos agentes, foi a consulta de enfermagem realizada pelos docentes. A mera designasão desta atividade parece ter substituído a necessária relação entre a teoria e a pratica. () depoimento abaixo ilustra como esta consulta encerra-se em sua propria forma: 
A ação principal da enfermeira é orientar o doente (transmitir um saber) e para tal é preciso conhecer suas necessidades, oblendo informaŁ̧ões atracés de um conjunto de questões adequadas a esse objetivo.

Retomando-se o depoimento sobre a finalidade da intervenção atraves da consulta, confirma-se o esvaziamento até de um saber técnico biologico neste instrumento.

$\Lambda$ consulta de enfermagem na liga parece ser mais uma forma de designação de qualquer abordagem realizada pelo enfermeiro.visando alguma assistência a saúde. Esta, no entanto, destituída de cientificidade não vem contribuindo para a qualificação das intervenções da enfermagem. $\Lambda$ legitimidade da produção de instrumentos de trabalho, tal como a consulta de enfermagem, e deslocada para as esferas jurídicas e científica. evitando dessa forma. enfrentar a concretitude da divisão social do trabalho presente historicamente também na enfermagem.

Dar significado a ação assistencial da enfermagem na ligga. passa pelo enfrentamento da realidade concreta desse trabalho, que aqui se está procurando compreender.

Em síntese, o processo de trabalho da enfermagem na liga se reduz a ser meio do processo de trabalho médico, tanto na sua face assistencial como na sua face de pesquisa.

$\mathrm{Na}$ face de assistencial, a enfermagem reitera o saber que sustenta a finalidade e o recorte do objeto do trabalho médico. Porem, este saber parece esvaziar-se como meio do processo de trabalho da enfermagem por ser mecanicista a-reflexivo e fragmentário.

Na face de pesquisa. limita-se à execução de procedimentos téenicos que instrumentalizam a pesquisa médica.

A ạ̣ão da enfermagem serve de apoio à pesquisa médica, colelando os dados e controlando as experiências.

Tendo o ensino sido representado eomo produto de u ma integração com a prática desenvolvida pelos docentes de enfermagem. essa fase do processo de trabalho termina por reproduzir o seu saber esvaziado de significado mas que por ser a-crítico legitima sua falsa neutralidade. No dizer de RLZENDE (1986), esta neutralidade "(...) e escamoteadora de seu compromisso social".

() estudo da dialética do processo de trabalho da enfermagem na Liga mostra sua congruencia com processo maior - a do trabalho medico - e, ainda. em todas as suas faces visíveis, uma práxis reiterativa do modelo hegemonico atual vigente na prática de assistência e do ensino em saúde. Esta prática na atualidade confronta-se dialeticamente com os princípios contidos na organização do Sistema Único de Saúde onde. " o rompimento com esse modelo 
hegemônico implica na conformação de uma nova consciência sanitária, em uma nova ética profissional, em um novo paradigma científico fundado em uma teoria social da doença, e, finalmente, em uma transformação das práticas sanitárias" (TEIXEIRA;MENDONÇA; 1989).

Sugere-se que a superação das contradições encontradas na presente investigação primeiramente deve passar pelo progressivo e contínuo processo de reflexão coletiva dos agentes sobre o seu trabalho, articuladas à compreensão dos processos de produção dos serviços de saúde.

CAR,M.R.: EGRY,E.Y. The labour nursing process in the ambulatorial assistance of bypertension : conceptions and contradictions. Rev.Esc.Enf.USP., v.29. n.2.p.180-92, aug. 1995.

This study deals with the health assistance phenomena in general, and the nursing assistance in particular, as it occurs in Hypertension League. Its main theoretical framework, supported by the historical and dialectical materialism, it the labour process theory and its elements: Finality, Object and Means/Intruments. The investigation reveals that the workers conceptions about their labour process express a reiterative, non-creative and non-reflexive praxis. The labour process of nursing assistance was reiterated with Mean to the medical labour process, and to be seem emptied of the an scientific knowledge.

IINITERMS: Labour process. Hypertension. Health of Adult

\section{REFERÊNCIAS BIBLIOGRÁFICAS}

ALMEIDA. M.C.P. O trabalho de enfermagem e sua articulaçáo com o processo de trabalho em saúde coletiva: rede básica de saúde em Ribeirăo Preto. Ribeirão Preto. 1991. $279 \mathrm{p}$ Tese (Livre-docência) - Escola de Enfermagem de Ribeirăo Preto, Universidade de São Paulo.

ALMEIDA. M.C.P; ROCHA. J.S.Y. O saber de enfermagem e sua dimensáo prática. São Paulo. Cortez. 1986.

CAR.M.R. Da aparência à esséncia a práxis assistencial dos trabalhadores da Liga de Hipertensào Arterial. Sáo Paulo,1993.125p.Tese(Doutorado)-Escola de Enfermagem. Universidade de Săo Paulo.

CASTELLANOS, B.E.P. O trabalho do enfermeiro - a procura e o encontro de um caminho para o seu estudo: da abordagem mecanico-funcionalista à pesquisa emancipatória. Săo Paulo. 1987. 395p. Tese (Doutorado). Escola de Enfermagem. Universidade de Sao Paulo..

FIORIN, J.L.; SAVIOLI, F.P. Para entender o texto: leitura e redação. Sáo Paulo. Ática, 1991. 
GERMANO, R.M. Educaçá e ideologia da enfermagem no Brasil. Sào Paulo. Cortez. 1985.

GIORGI. D.M.A. et al. Aderéncia ao tratamento em hipertensão arterial: influência de variáveis estruturais e de estratégias que visem sua melhora. Rev.Bras.Med.(Cardiol.). v.4. n.4, p. 167.76, 1985 .

GONÇALVES, R.B.M. O processo de trabalho em saúde. Sảo Paulo. Departamento de Medicina Preventiva da Faculdade de Medicina da USP. 1988. Mimeografado/

GONÇALVES, R.B.M. Práticas de saúde: processos de trabalho e necessidades. Săo Paulo. Departamento de Medicina Preventiva da Faculdade de Medicina da USP. 1992.I Mimeografado/

LAURELL, A.C. A saúde-doença como processo social. In: NUNES. E.D. (org.). Medicina social: aspectos históricos e teóricos. Sáo Paulo. Global. 1983. cap. 4. p. 133-58.

LAURELL,A.C.:BLANCO.J. Morbilidad. ambiente y organización social. In: INFANTE. N.B. de: ALVAREZ. L. Sociedad y salud. Cali, Formas Precisas, 1991 cap. 6. p. 425-42.

MELO, C. Divisao social do trabalho e enfermagem. São Paulo, Cortez. 1986

MINAYO, M.C.S O desafio do conhecimento: pesquisa qualitativa em saúde. São Paulo. Hucitec/ABRASCO, 1992.

PIERIN, A.M.G. et al. Atendimento de enfermagem ao paciente com hipertensao arterial Rev.Bras.Med. (Cardiol.). v. 3, n.4. p. 209-11, 1984

PIRES. D. Hegemonia médica na saúde e a enfermagem. São Paulo. Cortez. 1989.

REZENDE. A.L.M. Saúde: dialética do pensar e do fazer. Såo Paulo. Cortez. 1986.

SILVA. G.B. Enfermagem profissional: análise crítica. São Paulo. Cortez. 1986.

TEIXEIRA.S.F.:MENDONÇA:M.H. Reformas sanitárias na Itália e no Brasil:comparaçðes. In: TEIXEIRA:S.F.(org.) Reforma sanitária: em busca de uma teoria. Săo Paulo.Cortez/ ABRASCO. 1989. 